\title{
Patient Expectations and Perceptions of Goal-setting Strategies for Disease Management in Rheumatoid Arthritis
}

\author{
Vibeke Strand, Grace C. Wright, Martin J. Bergman, Jeyanesh Tambiah, and Peter C. Taylor
}

ABSTRACT. Objective. To identify how patients perceive the broad effect of active rheumatoid arthritis (RA) on their daily lives and indicate how RA disease management could benefit from the inclusion of individual goal-setting strategies.

Methods. Two multinational surveys were completed by patients with RA. The "Good Days Fast" survey was conducted to explore the effect of disease on the daily lives and relationships of women with RA. The "Getting to Your Destination Faster" survey examined RA patients' treatment expectations and goal-setting practices.

Results. Respondents from all countries agreed that RA had a substantial negative effect on many aspects of their lives (work productivity, daily routines, participation in social and leisure activities) and emotional well-being (loss of self-confidence, feelings of detachment, isolation). Daily pain was a paramount issue, and being pain- and fatigue-free was considered the main indicator of a "good day." Setting personal, social, and treatment goals, as well as monitoring disease progress to achieve these, was considered very beneficial by patients with RA, but discussion of treatment goals seldom appeared to be a part of medical appointments.

Conclusion. Many patients with RA feel unable to communicate their disease burden and treatment goals, which are critically important to them, to their healthcare provider (HCP). Insights gained from these 2 surveys should help to guide patients and HCP to better focus upon mutually defined goals for continued improvement of management and achievement of optimal care in RA. (First Release August 1 2015; J Rheumatol 2015;42:2046-54; doi:10.3899/jrheum.140976)

\section{Key Indexing Terms: RHEUMATOID ARTHRITIS QUALITY OF LIFE}

It is well established that rheumatoid arthritis (RA) negatively affects health-related quality of life (HRQOL), in particular the ability of patients to perform work ${ }^{1}$ within and outside the home $e^{2,3}$ and to participate in social and leisure activities ${ }^{4}$. Therefore, patient-reported HRQOL and participation are now widely recognized as important outcome measures when

From Division of Immunology/Rheumatology, Stanford University School of Medicine, Stanford, CA; New York University Langone Medical Center, New York, NY; Drexel University College of Medicine, Philadelphia, PA; UCB Pharma, Smyrna, GA, USA; Kennedy Institute of Rheumatology, Oxford, UK.

Funded by UCB Pharma. V. Strand, G.C. Wright, and M.J. Bergman are consultants for UCB Pharma; J. Tambiah is an employee and shareholder of UCB Pharma; Peter Taylor is a consultant for, and has received research grants from, $U C B$ Pharma.

V. Strand, MD, FACP, FACR, Biopharmaceutical Consultant; Adjunct Professor, Division of Immunology/Rheumatology, Stanford University School of Medicine; G.C. Wright, MD, New York University Langone Medical Center; M.J. Bergman, MD, Drexel University College of Medicine; J. Tambiah, MD, UCB Pharma; P.C. Taylor, MD, Kennedy Institute of Rheumatology.

Address correspondence to Dr. Strand, Biopharmaceutical Consultant, Adjunct Clinical Professor, Division of Immunology/Rheumatology, Stanford University School of Medicine, Portola Valley, California 94028, USA.E-mail: vstrand@stanford.edu

Full Release Article. For details see Reprints/Permissions at jrheum.org Accepted for publication June 4, 2015.

\section{PATIENT SURVEY PATIENT SATISFACTION}

assessing treatment efficacy in RA, allowing for better understanding of the correlation between different aspects of disease activity and its broad burden on patients ${ }^{5,6}$. Patient-reported outcomes (PRO), including global assessment of disease activity, pain, physical function, measures of HRQOL, and fatigue, are commonly used to assess efficacy in RA randomized controlled trials ${ }^{7}$, and their inclusion in clinical practice has become increasingly important $^{8,9}$. In addition, assessment of participation in RA, e.g., productivity, as well as engagement in family/social and leisure activities, offers value from both individual and societal perspectives ${ }^{5,10,11}$. It is, therefore, crucial to ascertain how patients with RA view their disease and its effect on their lives, and evaluate their expectations of treatment by clarifying their specific treatment goals ${ }^{12,13}$.

Despite recognition that active RA has a substantial effect on all aspects of daily life, challenges for HRQOL assessment and productivity/participation remain, such as validation and standardization of instruments ${ }^{5,14}$. Patients' emotional well-being and the role of their healthcare provider (HCP) in disease management are often not evaluated. Only a minority of patients discuss issues of pain, physical function, fatigue, HRQOL, and participation with their physician ${ }^{15}$.

Personal non-commercial use only. The Journal of Rheumatology Copyright $\odot$ 2015. All rights reserved 
The treat-to-target approach is an example of a goal-setting strategy that has been explored in a variety of clinical settings ${ }^{13}$. Although its value for effective RA disease management has been confirmed ${ }^{16,17}$, previous studies indicate that patients' and physicians' views differ regarding the effects of disease and setting appropriate treatment goals $^{18,19}$, and that implementing a treat-to-target strategy is associated with challenges ${ }^{20}$.

Here, we present the results of 2 surveys designed to analyze the effect of active RA on patients' lives. The "Good Days Fast" survey ${ }^{21}$ was conducted to explore disease effects on the daily lives and relationships of women with RA. The "Getting To Your Destination Faster" survey ${ }^{22}$ examined patients' expectations of treatment outcomes and goal-setting practices. The aim of both surveys was to identify how patients perceive the effects of RA and indicate how disease management could benefit from goal-setting strategies.

\section{MATERIALS AND METHODS}

Both surveys were initiated by UCB Pharma, and it was ensured that they adhered to the Market Research Society code of conduct and the International Code on Market and Social Research.

Good Days Fast survey. For this survey (conducted by Echo Research), 27,459 women were recruited through an online panel (managed by Lightspeed Research) from 7 countries (United States, Canada, United Kingdom, France, Germany, Italy, and Spain). Eligible patients were age $25-65$ years, with a self-reported diagnosis of RA $\geq 6$ months. Quantitative online interviews of 10-min duration were conducted between July 30 and August 31, 2009, with questions addressing aspects of the physical and emotional effects of RA. The target was at least 300 interviews per country. All responses were provided directly by survey participants without guidance from medical personnel.

The survey consisted of 19 questions, most of which provided predefined answer options, addressing patient demographics, self-assessed disease severity, effects of RA on daily activities, relationships, work productivity, emotional well-being, pain management, interactions with HCP, and perceptions of a "good day" (Supplementary Data available online at jrheum.org).

Getting to Your Destination Faster survey. This survey (conducted by Opinion Matters) was designed to examine patients' perceptions regarding disease management, treatment expectations, and goal-setting strategies. Participants were identified through their profile details registered on the agency's research panels, where they had indicated any conditions that existed in their households, followed by further screening questions. All participants went through a double opt-in process and agreed to participate in the survey. Participants were either entered into a prize draw or rewarded with points that could be redeemed for money or against charitable donations.

Men and women with RA from 6 countries (United States, United Kingdom, France, Germany, Italy, and Spain) were recruited between September 28 and November 2, 2010 using an online research panel to complete an Internet survey. Eligible patients were age 25-65 years, with a diagnosis of RA $\geq 6$ months; confirmation was not obtained that RA diagnosis had been clinically confirmed. Responses were provided directly by the participants without guidance from medical personnel.

The 26 survey questions, most of which provided predefined answer options, addressed patient demographics, disease effects on employment and relationships, the role of HCP in disease management, goal-setting strategies, and patients' awareness of the treat-to-target approach (Supplementary Data available online at jrheum.org).

Data analysis. Mean and percentage responses and 95\% CI to each question were computed for the overall patient population and relevant subpopulations for individual survey questions. Respondents whose answers were abnormally patterned (for example, using the same response for a majority of questions or answering the questionnaire too quickly) were eliminated from analysis. Other respondents removed from the database included those who missed questions or provided incomplete information.

\section{RESULTS}

Patient characteristics: Good Days Fast survey. There were 27,459 women recruited through the Internet; 1958 satisfied the screening criteria, completed the survey, and passed the quality control checks (Supplementary Table 1 available online at jrheum.org). For the United Kingdom, France, Germany, Italy, Spain, and the United States, the target of at least 300 interviews per country was achieved; 155 Canadian women completed the survey (Supplementary Table 1 available online at jrheum.org). Baseline characteristics were similar among the respective surveys (Supplementary Table 1 available online at jrheum.org). About one-third of patients (32\%) were 46-55 years old, mean age was 46 years ( \pm 10.4 SD), and the majority $(75 \%)$ had an RA diagnosis of $\geq 1$ year. Patients reported their disease activity as "moderate" in $57 \%$ and "severe" in $12 \%$ of cases, which was consistent across countries (Supplementary Table 1 and Supplementary Figure 1 available online at jrheum.org). A majority (69\%) indicated their relationship status as "Married" or "In a relationship" (Supplementary Table 1 available online at jrheum.org).

Patient characteristics: Getting to Your Destination Faster survey. A total of 1829 respondents completed the survey and passed the quality control checks. They were from the United Kingdom $(n=306)$, France $(n=306)$, Germany $(n=304)$, Italy $(\mathrm{n}=306)$, Spain $(\mathrm{n}=304)$, and the United States $(\mathrm{n}=$ 303). There were 139 respondents who were excluded from analysis because of not completing the entire survey; no similar characteristics were observed among these (data not shown). Overall, the majority of patients were in the 45-54 year age group; 1242 were women (68\%) and 587 men (32\%; Supplementary Table 1 available online at jrheum.org). The majority of respondents $(54 \%)$ reported their disease activity to be moderate, while $13 \%$ reported that it was severe; $57 \%$ were married (Supplementary Table 1 and Supplementary Figure 1, available online at jrheum.org).

Patients'views of the effects of RA on working life. For both surveys, the majority of patients reported they were employed (Good Days Fast: 57\%, Getting to Your Destination Faster: $55 \%)$; employment status varied substantially between countries (Supplementary Figure 2A available online at jrheum.org).

RA clearly had a negative effect on patients' work arrangements, productivity, and self-confidence. In the Good Days Fast survey, 23\% of women reported being forced to stop work; $17 \%$ had switched to part-time employment because of RA (Figure 1). Twenty-six percent stated that they had informed their employer about their condition, $22 \%$ indicated

Personal non-commercial use only. The Journal of Rheumatology Copyright $\odot$ 2015. All rights reserved 


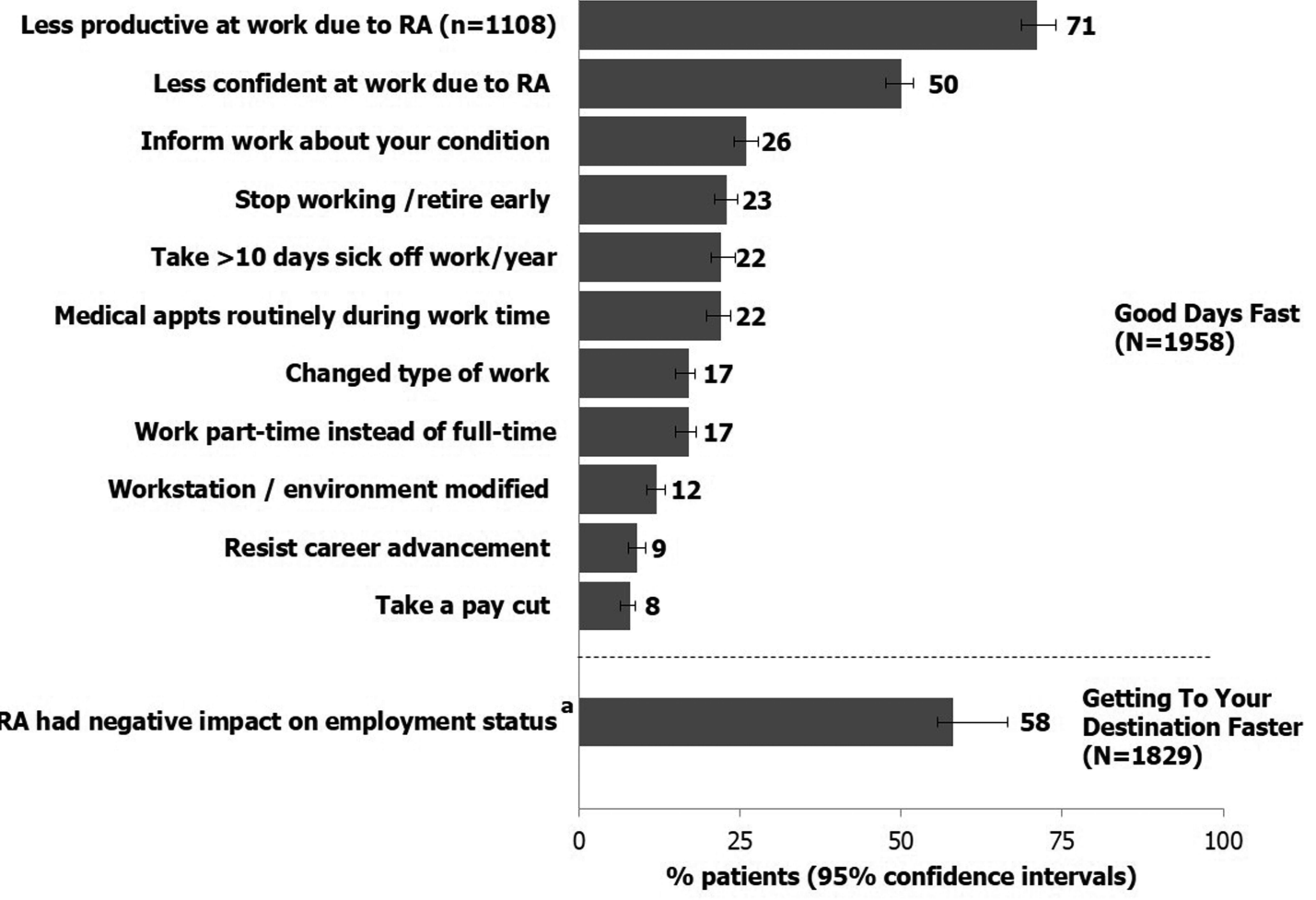

Figure 1. Work arrangements, productivity, and self-confidence at work as affected by RA. ${ }^{\text {a }}$ For example: Stopped working altogether, moved from full-time to part-time work, or forced to change job or role. RA: rheumatoid arthritis.

they regularly took $>10$ days off work each year, and $9 \%$ stated that RA had negatively affected career prospects (Figure 1). The highest proportion of patients affected by these issues were in Germany (13\%) and France (12\%; Supplementary Figure 2B available online at jrheum.org).

The majority of women (71\%) in the Good Days Fast survey agreed that they were less productive at work because of their condition; half of the women stated their self-confidence at work was negatively affected (Figure 1). Similarly, $58 \%$ of patients from the Getting to Your Destination Faster survey reported that RA negatively affected their employment status (Figure 1). Twenty-six percent of participants claimed they were not affected by any of the issues described.

Fewer UK and Canadian patients agreed they were less productive at work because of their condition; interestingly, only $32 \%$ of UK and US women reported struggling with self-confidence at work (Supplementary Figure 2C available online at jrheum.org). More patients in the United States (42\%), Canada (36\%), and the United Kingdom (33\%) had retired early versus continental Europe (France: 21\%, Germany: 19\%, Italy: 7\%, Spain: 9\%). In France, 25\% of patients had to change their type of work because of their illness, and $43 \%$ of Spanish patients reported attending medical appointments during working hours (Supplementary Figure 2B available online at jrheum.org).

Effects of RA on daily routine, social life, and leisure activ- ities. RA had an adverse effect on everyday activities, including participation in social/family/leisure activities. In the Good Days Fast survey, 60\% reported it was difficult to perform "normal" activities because of RA; $48 \%$ admitted to difficulties when making plans because of pain, mobility restrictions, and fatigue. Housework (39\%), sleeping (28\%), and shopping (24\%) were examples of activities that patients always found painful, more difficult, or had to stop altogether (Figure 2). Cooking was more difficult for $16 \%$, while $17 \%$ reported their ability to drive was affected. Importantly, many women felt their condition limited spontaneity (57\%) and forced compromises over enjoyable activities, such as choosing holiday destinations (42\%; Figure 2). RA also affected participation in leisure activities (keeping fit/playing sports: $46 \%$, gardening: $39 \%$, and enjoying outdoor activities: $33 \%$ ); however, southern European women appeared to be less affected than those in the United States (Supplementary Figure 3 available online at jrheum.org). Thirty-one percent reported their favorite hobby as painful, more difficult, or that they were forced to stop, while $16 \%$ found going out or entertaining at home was always more painful or difficult (Figure 2).

Emotional effects of RA. The negative effect of RA extended to many aspects of the patients' relationships with family, friends, and partners, as well as their overall emotional well-being. Isolation was a problem for $26 \%$ of women in the

Personal non-commercial use only. The Journal of Rheumatology Copyright ()$^{2015}$. All rights reserved. 


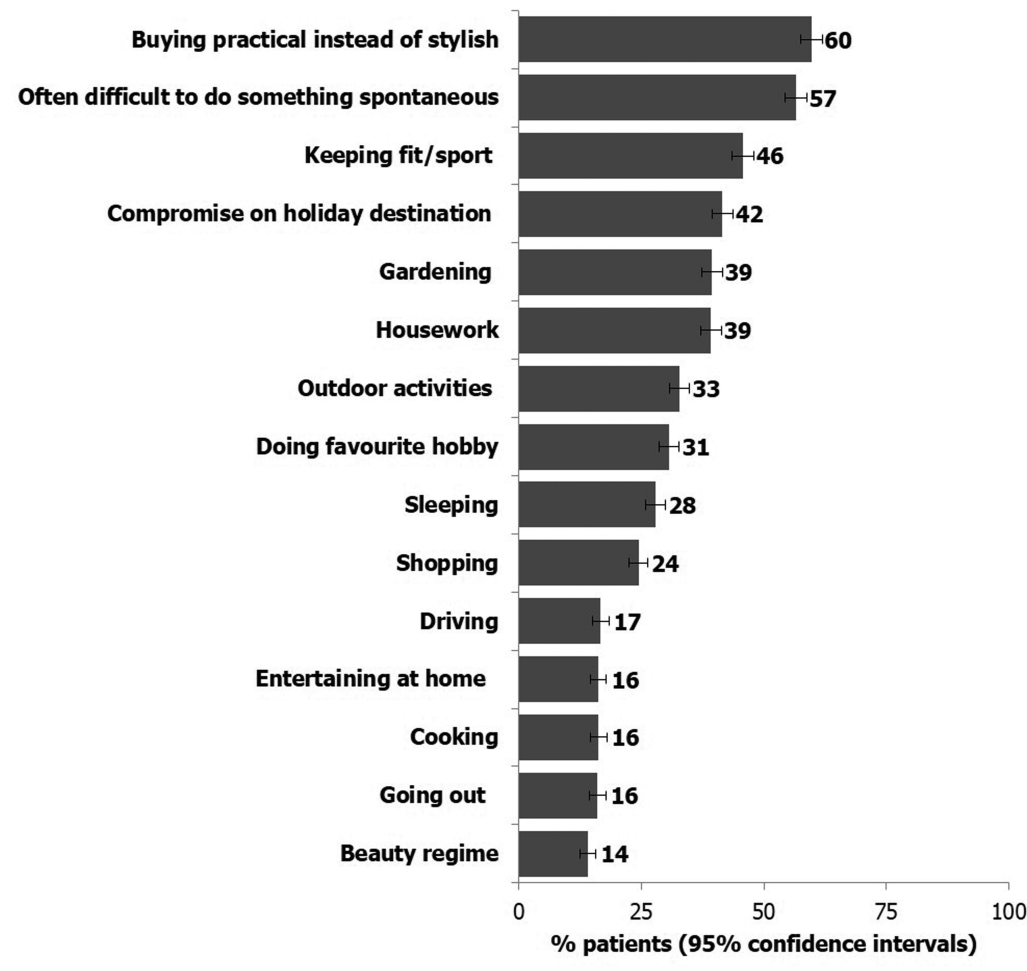

Figure 2. RA effects on home/social/leisure activities. Good Days Fast survey, $\mathrm{n}=1958$. RA: rheumatoid arthritis.

Good Days Fast survey, and 68\% admitted concealing their pain from others (Figure 3). Overall, 54\% felt that friends and family did not understand their pain or fatigue; $32 \%$ stated that RA had affected their closest relationships for the worse, for example, by preventing them from playing with children or grandchildren (Figure 3).

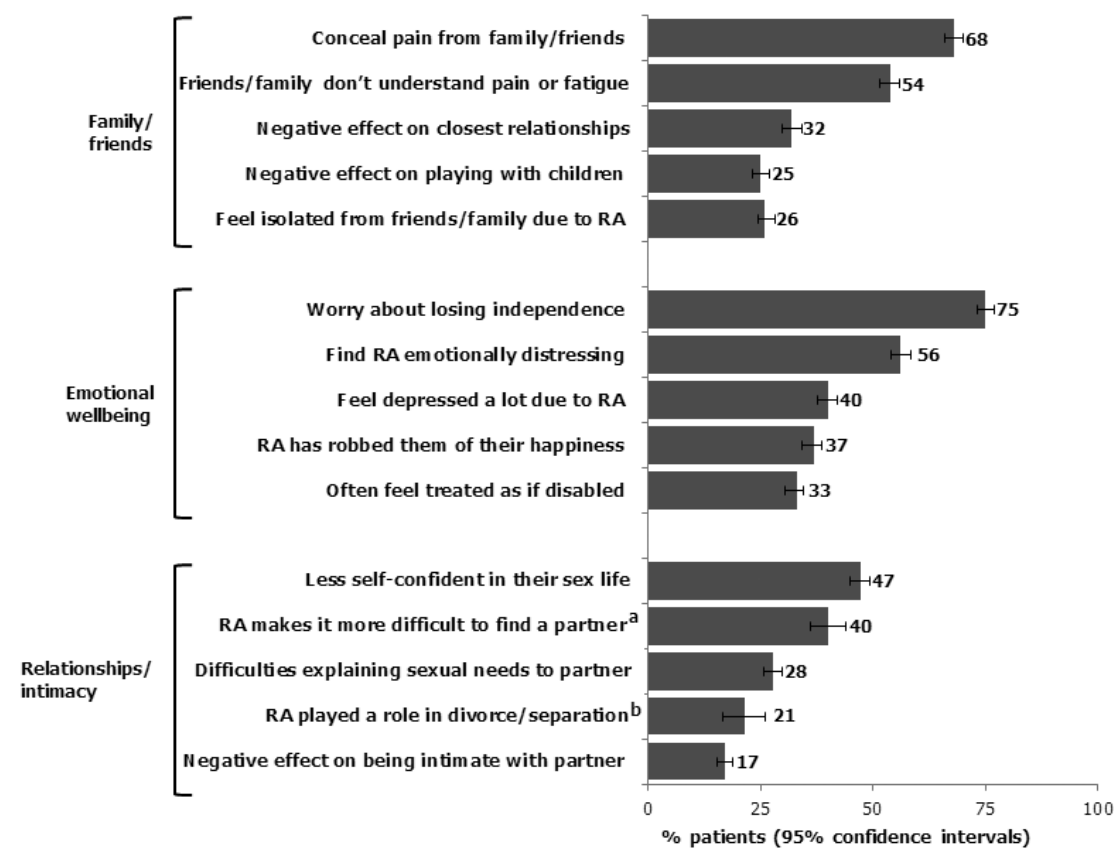

Figure 3. Emotional effect of RA. Good Days Fast survey, $\mathrm{n}=1958$. ${ }^{\mathrm{a}}$ Single $(\mathrm{n}=611) .{ }^{\mathrm{b}}$ Divorced/ separated $(n=295)$. RA: rheumatoid arthritis. 
Loss of independence was a key concern for $75 \%$ women, with 1 in 3 reporting they often felt treated as if they were disabled (Good Days Fast survey). Many women described feeling distressed (56\%) and depressed (40\%) because of their RA (Figure 3). These feelings extended to their relationships with their partners. Generally, $17 \%$ reported a negative effect on or less confidence (47\%) when being intimate with their partner, and $28 \%$ struggled to explain their sexual needs to their partners (Figure 3). RA had played a significant role in the decision to separate or divorce for $21 \%$ patients, and $40 \%$ agreed that RA made it more difficult to find a partner (Figure 3).

Pain. In the Good Days Fast survey, 63\% stated they experienced pain every day, and $75 \%$ were currently taking pain medication (Figure 4). Importantly, survey results clearly demonstrated that a majority of patients (67\%) were constantly looking for new ideas to manage their pain and that $80-87 \%$ discussed their pain and levels of tiredness/fatigue with their doctors (Figure 4). Results were similar across countries (Supplementary Table 3 available online at jrheum.org).

Despite these reports, many patients indicated problems discussing their pain with their HCP. The majority of women (73\%) in the Good Days Fast survey felt that they were complaining when discussing their RA symptoms, 55\% admitted to feeling too shy to talk about how much pain they experienced, and 54\% did not talk about how to best control their pain (Figure 4).

The observations of how patients perceived and managed pain varied between countries: $85 \%$ of US women indicated they had daily pain and $82 \%$ reported daily use of pain medications, whereas only $41 \%$ of Italian women indicated daily pain, with $63 \%$ taking pain relief. US patients appeared more forthcoming when voicing their concerns about the pain experienced, although a high proportion still felt too shy $(40 \%)$ or unable to discuss their pain (42\%; Supplementary Table 3 available online at jrheum.org).

Definition of a "good day." When asked what defined a "good day," $29-31 \%$ of patients reported that rapid pain relief, no morning stiffness, and being able to do everyday activities easily characterized a "good day"; $26 \%$ indicated being able to participate in outdoor activities was important (Figure 5). Patients offered examples from various aspects of their daily lives, but the majority characterized a "good day" as being free of fatigue (58\%) and pain (57\%; Figure 5).

Patient expectations and perceptions of treatment goals. In the Getting to Your Destination Faster survey, patients reported a variety of obstacles to controlling their RA symptoms, namely lack of education/understanding of RA (16\%), personal resolve (11\%), and/or assistance from their physician (11\%). The majority (54\%) considered finding the right treatment option as the main issue hindering disease management. Seventy percent agreed that pain relief was the most important aspect; reduced joint stiffness, improved work or home productivity, and relief from fatigue ranked much lower $(17 \%, 7 \%$, and $6 \%$, respectively). According to the Getting to Your Destination Faster survey, $81 \%$ of respondents claimed that they would set themselves personal, social, and treatment goals when starting a new therapy (Supplementary Table 2, available online at jrheum.org), and $91 \%$ claimed they set goals for themselves when starting a new drug.

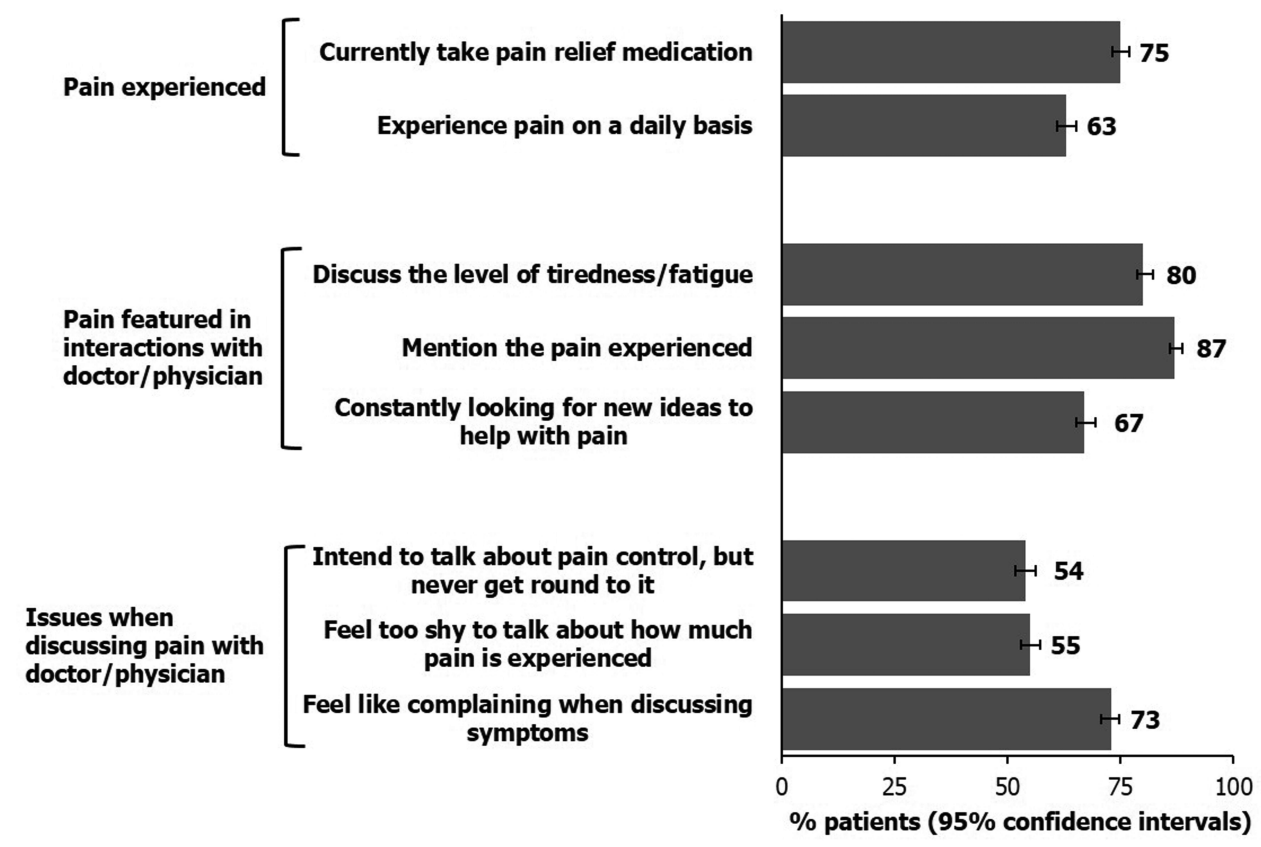

Figure 4. Patients' assessments of pain. Good Days Fast survey, n = 1958. 


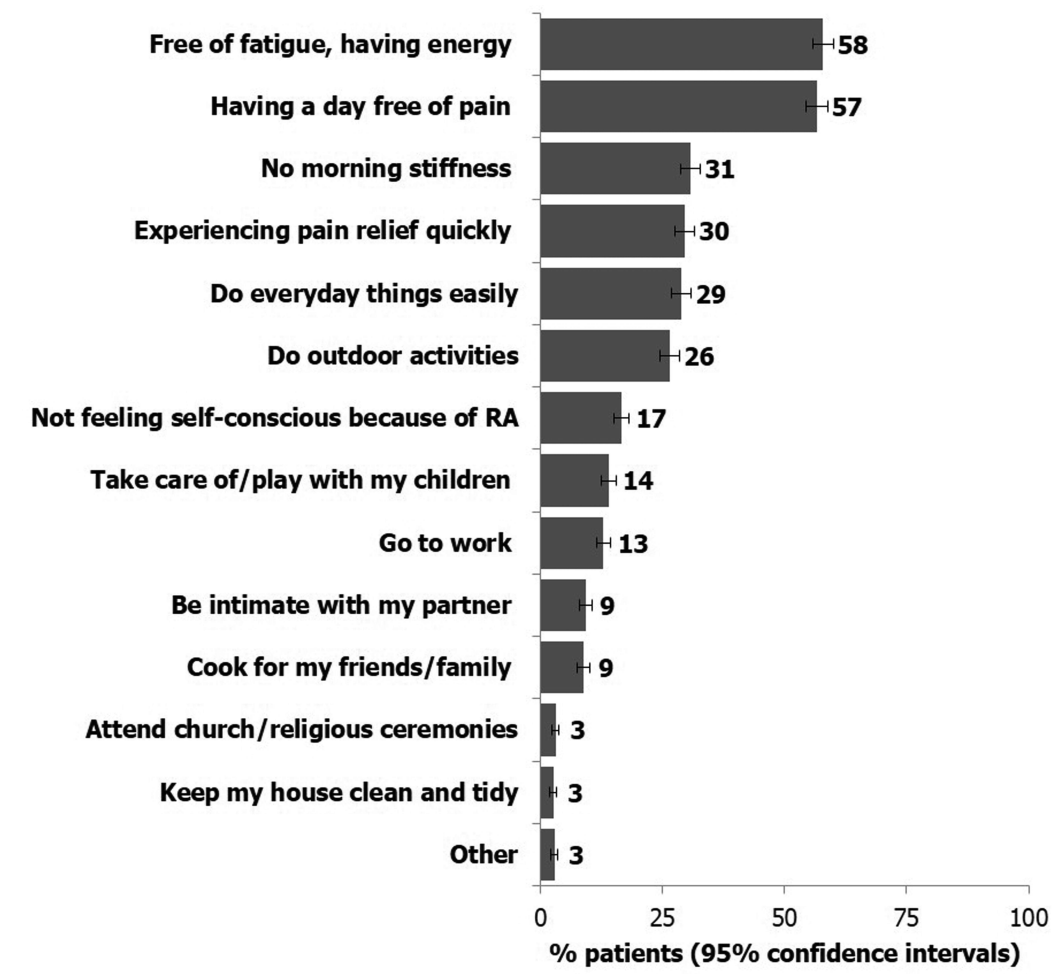

Figure 5. Definition of a "good day.” Good Days Fast survey, n = 1958.

Patient perceptions of treat-to-target approach for $R A$ management. Patients strongly agreed that setting goals was beneficial because it allowed them to assess treatment success $(86 \%)$ and/or made them feel more positive (87\%; Figure $6 \mathrm{~A})$. Eighty-four percent echoed that having a treatment that got them to their targets fast was important. Discussion of goals with their HCP was considered important by $88 \%$ patients; $67 \%$ thought it would be helpful if their HCP provided examples. Over $90 \%$ indicated "having a good day" as their preferred target (Figure 6A).

When asked about their perceptions, $64 \%$ of participants stated that setting personal, lifestyle, and treatment goals as well as monitoring disease progression to achieve these were key elements for a targeted approach for disease management (Figure 6A). Development and adherence to a strict treatment plan was an important consideration for 44\% . Overall, 27\% agreed that receiving stronger pain relief medications and more frequent and longer appointments with HCP (26\%) should be part of a targeted treatment plan (Figure 6A).

It is noteworthy that although they might have heard about the concept, 1 in 10 patients claimed not to know what comprised a treat-to-target approach (Figure 6B), even though $87 \%$ agreed that establishing treatment targets would have a positive effect on their disease management (Figure 6B). Importantly, 73\% stated that their HCP did not discuss treating RA with an approach that included setting targets, while $60 \%$ of respondents had not heard of the treat-to-target approach; $61 \%$ reported that their HCP did not manage their disease with strict goals and timeframes in place (Figure 6B). Positively, 62\% claimed to share decisions with their HCP regarding how best to manage their RA, although $76 \%$ expressed a desire for more detailed discussions about setting treatment goals (Figure 6B).

\section{DISCUSSION}

As expected, respondents reported that RA had a substantial effect on many aspects of their lives, including work productivity, daily routines, and participation in social and leisure activities. Despite all available new therapies, daily pain continues to be a paramount issue, and being pain- and fatigue-free is considered the main indicator of a "good day." Since the majority of patients with RA are women, the findings of the Good Days Fast survey can be regarded as a poignant representation of the issues this patient population encounters. Survey responses clearly emphasized a much deeper hidden disease effect, indicated by loss of self-confidence, and feelings of detachment, isolation, and distress that affected patients' emotional well-being and relationships with family, friends, and partners.

From the patients' perspective, a targeted approach for disease management, consisting of setting personal, social, and treatment goals, as well as monitoring disease progress to achieve these, is clearly considered very beneficial. Yet discussion of goals or targets seldom appears to be a part of appointments with their doctor. This is in agreement with other studies, demonstrating that most physician-patient

Personal non-commercial use only. The Journal of Rheumatology Copyright (c) 2015. All rights reserved. 
A) Patient perceptions of goal setting and of a targeted approach to disease management

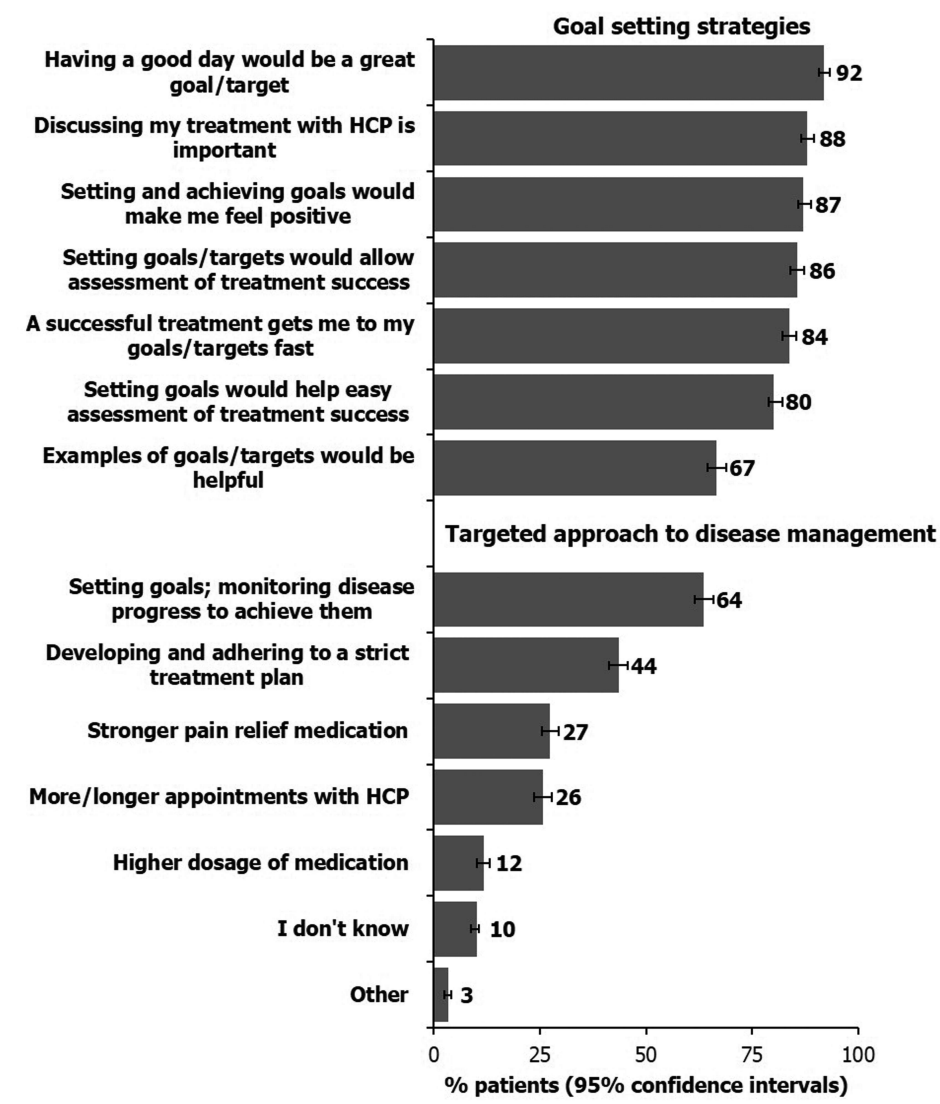

B) Patient perceptions of the HCP role in RA management

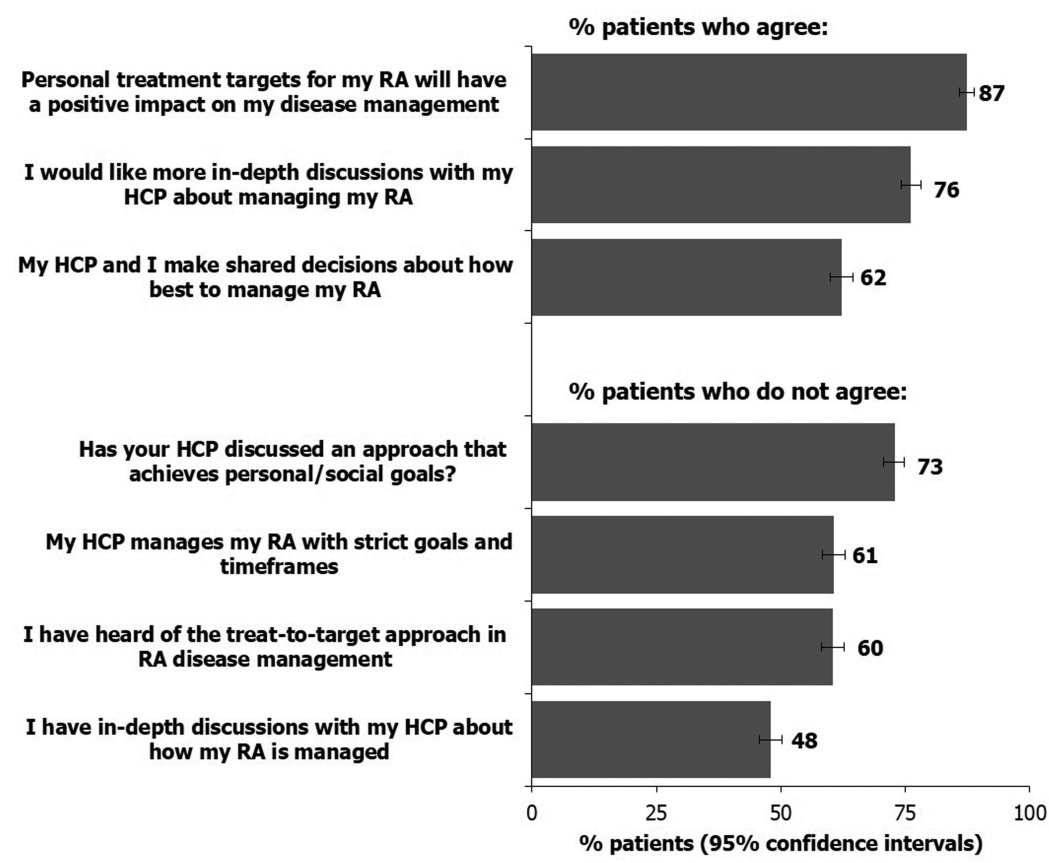

Figure 6. Patient perceptions of goal-setting strategies and the role of HCP in RA management. Getting to Your Destination Faster survey, $\mathrm{n}=1829$. HCP: healthcare provider; RA: rheumatoid arthritis. 
communications focus on symptoms or treatment options rather than patients' perspective of HRQOL ${ }^{15,23}$. It has been reported that patients and physicians consider different aspects of RA when making treatment decisions ${ }^{24,25,26}$, and the results reported here clearly indicate that, from the patients' perspective, significant room for improvement exists in such discussions. Although respondents claimed they share decisions about their RA treatment regimens with their $\mathrm{HCP}$, many are unable to adequately express their disease burden and the treatment goals critically important to them. HCP should, therefore, initiate more detailed discussions with their patients about expectations and aim to explain treat-to-target approaches and other goal-setting strategies more carefully.

The aim of the treat-to-target approach has been defined as the attainment of remission or low disease activity (LDA) as an alternative goal in patients with longstanding disease ${ }^{13}$. Although the importance of patient involvement was strongly emphasized when the treat-to-target approach was first established ${ }^{12}$, achievement of LDA has been associated with only modest improvements in $\mathrm{PRO}^{27}$. Patients can be reluctant to embrace the treat-to-target strategy ${ }^{20,28}$, possibly because they feel it does not address aspects of RA management important to them ${ }^{29}$, and it has been questioned whether the treat-to-target strategy places too much emphasis on quantifiable disease activity scores rather than $\mathrm{PRO}^{20}$.

Appropriate goal setting may be particularly important for patients failing to meet the targets of LDA or remission. It is very interesting that both surveys indicate that patients have clear therapy goals that are quite congruent with the treat-to-target approach espoused by HCP, despite patients' lack of familiarity with the term. It appears that what is required is a bridge between identification of patient-specific goals and how physicians define realistic treatment expectations. Perhaps a part of this disconnect may be attributed to the fact that even after approval of 11 disease-modifying antirheumatic drugs (DMARD) since 1998, our current therapeutic armamentarium does not offer cures and still leaves many patients reporting that control of pain and fatigue remains an almost daily challenge. Other barriers to successful implementation of a treat-to-target approach could be that many patients with RA are not being treated with DMARD, do not have access to a rheumatologist familiar with the concept, and/or are reluctant to pursue a treat-to-target strategy because they do not feel the need for it or are worried about changing treatment ${ }^{17}$.

Limitations of the surveys described include a potential bias in recruitment because of the self-reported RA diagnosis and assessment of disease severity. Perhaps this explains the low percentage of patients self-reporting treatment with DMARD, although this is consistent with US marketing surveys. Both surveys were completed online, thus favoring patients able to afford or have access to a computer and not too ill to complete the questionnaires. There are no data regarding the occurrence and severity of effects on life of the various issues identified in the context of patients' disease activity, or how many were excluded from data analysis for the Good Days Fast survey and if their characteristics were similar to those not excluded. It should also be verified that the results are not dependent on country-specific treatment differences. The lack of a comparator population and the small sample sizes also represent significant limitations of the data presented, as is the fact that subpopulations have not been specified. One might also assume that those patients least satisfied with their treatment would be most likely to complete these surveys. Nonetheless, the similarity of reports by patients across countries and both surveys, and parallel findings with another survey where the diagnosis of RA had been confirmed ${ }^{23}$, offers confidence in the presented findings. Despite these limitations, similarities between the answers from participants across multiple countries lend credibility to a consistent theme of a disconnect between healthcare directives and patient perspectives.

It is evident that we need to better understand the nature of unmet patient needs because they relate to levels of disease management that differ from those achievable with medication. These needs are generally less obvious to friends, family, and colleagues of people with RA because they focus on aspects that differ from established disease management strategies; nonetheless, their effects on the individual, families, and societies are substantial.

We have a collective responsibility to better understand them and further improve the optimal management approaches for individuals failing to meet ideal, aspirational treatment targets of remission. Initiatives to identify, develop, and implement evidence-based and patient-centered standards of RA care, understandable to patients and professionals alike, are currently under way and will contribute to more unified treatment approaches across different countries ${ }^{30,31}$. By further investigating the spectrum of unmet need as it relates to optimal inflammation suppression using existing therapeutics, we will be able to inform desirable outcomes to be attained in future strategies. Insights gained from these 2 surveys should help to guide patients with RA and HCP to better focus on mutually defined goals for improvement in management of optimal care in RA.

\section{ACKNOWLEDGMENT}

The authors thank the patients who took part in this study and acknowledge Irfan Khan, Elizabeth Smith, and Sarah Kennedy (UCB Pharma, Atlanta, Georgia, USA) for publication management, Cathy O'Brien for statistical interpretation and development, and Costello Medical Consulting for editorial and administrative support.

\section{ONLINE SUPPLEMENT}

Supplementary data for this article are available online at jrheum.org.

\section{REFERENCES}

1. Burton W, Morrison A, Maclean R, Ruderman E. Systematic review of studies of productivity loss due to rheumatoid arthritis. Occup Med 2006;56:18-27.

Personal non-commercial use only. The Journal of Rheumatology Copyright (C) 2015. All rights reserved. 
2. Allaire SH, Meenan RF, Anderson JJ. The impact of rheumatoid arthritis on the household work performance of women. Arthritis Rheum 1991;34:669-78.

3. Habib G, Artul S, Ratson N, Froom P. Household work disability of Arab housewives with rheumatoid arthritis. Clin Rheumatol 2007;26:759-63.

4. Katz PP, Morris A, Yelin EH. Prevalence and predictors of disability in valued life activities among individuals with rheumatoid arthritis. Ann Rheum Dis 2006;65:763-9.

5. Strand V, Singh JA. Newer biological agents in rheumatoid arthritis: impact on health-related quality of life and productivity. Drugs 2010;70:121-45.

6. Russell AS, Gulliver WP, Irvine EJ, Albani S, Dutz JP. Quality of life in patients with immune-mediated inflammatory diseases. J Rheumatol Suppl 2011;88:7-19.

7. Her M, Kavanaugh A. Patient-reported outcomes in rheumatoid arthritis. Curr Opin Rheumatol 2012;24:327-34.

8. Ward V, Hill J, Hale C, Bird H, Quinn H, Thorpe R. Patient priorities of care in rheumatology outpatient clinics: a qualitative study. Musculoskeletal Care 2007;5:216-28.

9. Taylor P, Manger B, Alvaro-Gracia J, Johnstone R, Gomez-Reino J, Eberhardt E, et al. Patient perceptions concerning pain management in the treatment of rheumatoid arthritis. J Int Med Res 2010;38:1213-24.

10. Strand V, Khanna D. The impact of rheumatoid arthritis and treatment on patients' lives. Clin Exp Rheumatol 2010;28 Suppl 59:S32-40.

11. Jacobs P, Bissonnette R, Guenther LC. Socioeconomic burden of immune-mediated inflammatory diseases - focusing on work productivity and disability. J Rheumatol Suppl 2011;88:55-61.

12. de Wit MP, Smolen JS, Gossec L, van der Heijde DM. Treating rheumatoid arthritis to target: the patient version of the international recommendations. Ann Rheum Dis 2011;70:891-5.

13. Smolen JS, Aletaha D, Bijlsma JW, Breedveld FC, Boumpas D, Burmester G, et al; T2T Expert Committee. Treating rheumatoid arthritis to target: recommendations of an international task force. Ann Rheum Dis 2010;69:631-7.

14. Sokka T, Rannio T, Khan NA. Disease activity assessment and patient-reported outcomes in patients with early rheumatoid arthritis. Rheum Dis Clin North Am 2012;38:299-310.

15. McInnes IB, Combe B, Burmester G. Understanding the patient perspective - results of the Rheumatoid Arthritis: Insights, Strategies $\&$ Expectations (RAISE) patient needs survey. Clin Exp Rheumatol 2013;31:350-7.

16. Jurgens MS, Welsing PM, Jacobs JW. Overview and analysis of treat-to-target trials in rheumatoid arthritis reporting on remission. Clin Exp Rheumatol 2012;30 Suppl 73:S56-63.

17. Solomon DH, Bitton A, Katz JN, Radner H, Brown EM, Fraenkel L. Review: treat to target in rheumatoid arthritis: fact, fiction, or hypothesis? Arthritis Rheumatol 2014;66:775-82.
18. Hewlett S, Smith AP, Kirwan JR. Values for function in rheumatoid arthritis: patients, professionals, and public. Ann Rheum Dis 2001;60:928-33.

19. Wen H, Ralph Schumacher H, Li X, Gu J, Ma L, Wei H, et al. Comparison of expectations of physicians and patients with rheumatoid arthritis for rheumatology clinic visits: a pilot, multicenter, international study. Int J Rheum Dis 2012;15:380-9.

20. Ruderman EM. Treating to target in rheumatoid arthritis challenges and opportunities. Bull Hosp Jt Dis 2013;71:214-7.

21. Strand V, Emery P, Fleming S, Griffin C. The impact of rheumatoid arthritis (RA) on women: focus on pain, productivity and relationships. Arthritis Rheum 2010;62:S443.

22. Strand V, Taylor P, Sensky T, Harta N, Fleming S. Expectations of treatment goals and goal-setting practices in people with rheumatoid arthritis. Arthritis Rheum 2011;63 Suppl 10:S36.

23. Wollenhaupt J, Ehlebracht-Koenig I, Groenewegen A, Fricke D. Prioritizing the patient: optimizing therapy in rheumatoid arthritis. Results of a patient questionnaire in northern Germany. Open Access Rheumatology: Research and Reviews 2013;5:51-67. [Internet. Accessed July 6, 2015.] Available from: http://www.dovepress.com/prioritizing-the-patient-optimizingtherapy-in-rheumatoid-arthritis-re-peer-reviewed-article-OARRR

24. Robinson SM, Walker DJ. Negotiating targets with patients: choice of target in relation to occupational state. Rheumatology 2012;51:293-6.

25. van Hulst LT, Kievit W, van Bommel R, van Riel PL, Fraenkel L. Rheumatoid arthritis patients and rheumatologists approach the decision to escalate care differently: results of a maximum difference scaling experiment. Arthritis Care Res 2011;63:1407-14.

26. Otter SJ, Lucas K, Springett K, Moore A, Davies K, Young A, et al. Identifying patient-reported outcomes in rheumatoid arthritis: the impact of foot symptoms on self-perceived quality of life. Musculoskeletal Care 2012;10:65-75.

27. Curtis JR, Shan Y, Harrold L, Zhang J, Greenberg JD, Reed GW Patient perspectives on achieving treat-to-target goals: a critical examination of patient-reported outcomes. Arthritis Care Res 2013;65:1707-12.

28. Pincus T, Castrejón I, Bergman MJ, Yazici Y. Treat-to-target: not as simple as it appears. Clin Exp Rheumatol 2012;30 Suppl 73:S10-20.

29. Almoallim H, Kamil A. Rheumatoid arthritis: should we shift the focus from "Treat to Target" to "Treat to Work?". Clin Rheumatol 2013;32:285-7.

30. Petersson IF, Strombeck B, Andersen L, Cimmino M, Greiff R, Loza E, et al; eumusc.net-working group. Development of healthcare quality indicators for rheumatoid arthritis in Europe: the eumusc.net project. Ann Rheum Dis 2014;73:906-8.

31. Stoffer MA, Smolen JS, Woolf A, Ambrozic A, Bosworth A, Carmona L, et al; eumusc.net-working group. Development of patient-centred standards of care for rheumatoid arthritis in Europe: the eumusc.net project. Ann Rheum Dis 2014;73:902-5. 